\title{
A Structural Equation Model Estimation of the Role of Social Vulnerability as a Predictor of People's Feelings of Unsafety
}

\author{
Riccardo Valente $^{1}$ (D) $\cdot$ Sergi Valera Pertegas ${ }^{2} \cdot$ Joan Guàrdia Olmos $^{3}$
}

Accepted: 5 October 2018

(c) Springer Nature B.V. 2018

\begin{abstract}
People's perception of insecurity is linked to a wide range of factors and up-to-date sources stress the impact of socially constructed concerns on feelings of unsafety. Building further on recent developments, the present research proposes a measure of social vulnerability focusing on future-oriented anxieties and self-perceived social exclusion as predictors of subjective perceptions of insecurity. Data gathered in a large-scale survey in Italy $(\mathrm{N}=15,428)$ were analysed by implementing structural equation modeling in an attempt to address people's vulnerability beyond the mere consideration of the likelihood of individuals' involvement as the victims of a crime. The results provide evidence for the predictive role of social vulnerability on neighbourhood-based worries, victimization patterns and community cohesion. Moreover, the analysis show that health and financial precariousness, together with the perception of being marginalized or in some way excluded from society, may result in higher levels of subjective insecurity.
\end{abstract}

Keywords Vulnerability $\cdot$ Social insecurity $\cdot$ Feelings of unsafety $\cdot$ Structural equation modeling

\section{Introduction}

Fear of crime and the perception of insecurity are complex social issues that involve a variety of multi-faceted factors. Individuals' perceived insecurity has been associated with personal experiences with crime (Rader 2004), cognitive factors linked to people's appraisal of the risk of involvement as the victim of a crime (Jackson 2011), the characteristics of the places in which they live (Van Ham et al. 2012) and carry out daily activities (Pratt and Turanovic 2015) as well as the degree of community cohesion and collective efficacy for coping with security issues (Sampson 2012). At the same time, recent research increasingly

Riccardo Valente

valente_riccardo@hotmail.it; valente_riccardo@ub.edu

1 Department of Psychology and Education Sciences, Open University of Catalona, Rambla Poblenou, 156, 08018 Barcelona, Spain

2 Department of Social Psychology, University of Barcelona, Barcelona, Spain

3 Department of Methodology of Behavioral Sciences, Faculty of Psychology, University of Barcelona, Barcelona, Spain 
emphasizes the influence of social vulnerability on the perception of insecurity. Studies on the social determinants of insecurity led to a new line of research focusing on what Hirtenlehner (2008: 127) called the "generalized syndrome of insecurity" suggesting that citizens' insecurity may be connected to a wide range of existential uncertainties rather than to crime-related issues. Following recent developments exploring the link between social vulnerability and the perception of insecurity, the present research provides an overview of the results that arose from the analysis of a large-scale survey administered in Italy in an attempt to explore the incidence of socially constructed fears among Italian respondents.

\section{Fear of Crime, Perceptions of Insecurity and the Vulnerability Perspective}

In light of the considerable advances achieved by previous research in the field of fear of crime studies, it is nowadays possible to affirm that people's feelings of insecurity are linked to a wide range of factors that go beyond the mere consideration of crime and victimization experiences. In fact, while it may be reasonable to assume that high crime rates would engender high levels of fear among residents, it may also be the case that the perception of insecurity is high in contexts where comparatively low levels of crime are reported to the police (Valera and Guàrdia 2014). A review of the literature reveals the existence of different explanatory models used to understand the underlying patterns that influence people's perception of insecurity (Franklin et al. 2008; Kanan and Pruitt 2002; Rader et al. 2012). While some of these models are mainly focused on people's personal experiences with crime, other models explored socio-geographic and context-based determinants of fear as well as the role of social values and community cohesion for determining variations in terms of perceived insecurity.

Previous research emphasized, for instance, the relationship existing between environmental characteristics, on the one hand, and the perception of social and physical disorder, on the other. In the words of Hunter (1978), visible signs of physical deprivation, burnedout buildings or the presence of rubbish on the streets transmit an image of disorder which, in turn, increases feelings of living in a physically and socially-disrupted context. According to Ferraro (1995), antisocial behaviours may engender a sensation of the absence of a shared moral order which, in turn, increases feelings of living in a physically and socially-disrupted context. Similarly, Kohm (2009) stressed the role of physical disorder in determining neighbours' insecurity even in contexts where crime is actually low. Studies addressing the relationship between social and environmental disorders have traditionally been linked to the "broken windows theory" developed by Wilson and Kelling (1982). These authors make the case that people who perceive their neighbourhood as a "disorderly" place tend to be more worried about their safety in general (Swatt et al. 2013; Wyant 2008). However, recent studies have questioned the theory, calling for a reinterpretation of the concept of coexistence in urban spaces (Bannister et al. 2006; Hinkle 2015; Phillips and Smith 2006). From this perspective, scholars have developed noteworthy analysis on residential satisfaction, place attachment or place identification and their moderating effects on perceived insecurity (Pitner et al. 2012; Scannell and Gifford 2010). As a result of these contributions, a consistent branch of the literature shows support for the inverse relation between place attachment and fear of crime. In other words, the feeling of living in a familiar place, in which people have a sense of identification and feel as though they can 
rely on help from other neighbours in case of need usually has a positive effect on feelings of subjective wellbeing (McNamara et al. 2013).

However, perhaps the most consistent explanations of fear of crime and perceptions of insecurity currently fall under the so-called vulnerability hypothesis, which is reflected in a large body of empirical research (Jackson 2009; Killias 1990; Perloff 1983; Sacco and Glackman 1987). According to this hypothesis, individuals who (1) have a higher exposure to risk, (2) are likely to incur more serious consequences should they be the victims of a crime, and (3) are less likely to be able to control a situation in which they become a victim, are more likely to develop higher levels of fear of crime. As explained by Rader et al. (2012), the vulnerability perspective identified a set of variables associated with two forms of vulnerability - physical and social vulnerability - that could predict variations in terms of subjective insecurity. Numerous studies provided empirical support to the relationship between socio-demographic variables and the perception of insecurity, particularly with reference to age and gender. In fact, in spite of certain critical positions (Reid and Konrad 2004), many studies indicate that women and the elderly are more likely to experience comparatively higher levels of fear of crime. Authors such as Cossman and Rader (2011) for instance, explained that people who perceive themselves to be physically vulnerable tend to develop higher levels of insecurity. As for social vulnerability, Hanslmaier (2013) has stressed the role played by vulnerability in influencing one's sense of wellbeing and, in some circumstances, high levels of actual or perceived vulnerability may even cause people to adopt restricted behaviours and to avoid contact with places and/or social groups that they perceive as threatening or dangerous (San Juan et al. 2012).

Despite a growing theoretical and scientific base, the literature on social vulnerability has been sparse and generally focused on vulnerability with regards to victimization, while comparatively less attention has been paid to the role played by social exclusion in determining people's feelings of unsafety. The present research attempts to fill this gap and deepen the understanding of the influence that social determinants have on subjective feelings of insecurity. First, it is necessary to begin with a definition of social vulnerability that includes a focus on the negative perception of one's own living condition, which may lead to a process of social discomfort and, in turn, engender a spill-over effect on an individual's understanding of security issues in their immediate environment. More concretely, the proposed conceptualization aims to analyse the relationship between social vulnerability and feelings of unsafety by taking into account psychosocial factors associated with futureoriented anxieties and people's self-reported perception of social exclusion. This type of approach is based upon the work of Panzanis (2000: 417) who suggested that "a consideration of other insecurities should illuminate a richer and more complex understanding of people's experiences of safety in relation to crime".

\subsection{Social Vulnerability and Subjective Feelings of Unsafety: The Italian Scenario}

Exploring the influence of social vulnerability on a more generalized feeling of unsafety appears to be particularly appropriate in the context of a study developed in Italy, where socio-economic indicators have deteriorated significantly and people feel increasingly worried about their future.

According to the figures published by the Italian National Institute of Statistics (ISTAT 2017), the incidence of absolute poverty increased to $7.6 \%$ of the population in 2015 , which would translate into a total of 4.6 million people, the highest figure since 2005 . More than one out of four residents $(28.7 \%)$ are considered at risk of poverty or social 
exclusion which means, according to the definition provided within the framework of the Europe 2020 Strategy (Eurostat 2013), they are experiencing at least one of the following conditions: risk of poverty, serious material deprivation, or living in a low work intensity household. In particular, those who live in families with at least one foreign national are twice as likely to be exposed to the risk of poverty or social exclusion (49.5\%) compared to those living in families with only Italians (26.3\%). In 2016, Italy registered the highest percentage of NEETs ("not engaged in education, employment or training") among the countries of the European Union (24.3\%), against an average value of $14.2 \%$. Italy is affected by a steady process of population ageing, with an ageing index that places the country among those with the largest ageing population in the world. Lastly, gender gaps in employment rates are also noticeable: despite the higher level of education among working-age women (53.8\% have a degree compared to $49.2 \%$ of men), in 2016 the female employment rate for women aged between 15 and 64 years was $48.1 \%$, well below the male employment rate $(66.5 \%)$.

With reference to public security, Ministry of the Interior announced a $12 \%$ decrease in recorded crime compared to the prior year during the annual press release of the Committee on Public Safety and National Security that was broadcasted in August 2017. In particular, violent crime and property crimes decreased: homicides registered a decline of $15 \%$, there were 80,000 fewer thefts than the year before (a decrease of $10.3 \%$ ) and robberies also decreased by $11.3 \%$ (Ministero dell'Interno 2017). The drop in crime rates is even more evident when considering longitudinal data provided by Rizzo (2017): 2771,490 crimes were reported in 2006 compared to 2687,249 in 2015; in 19911773 murders were committed, in 2016 there were 245; bank robberies have dropped by $90 \%$ over the past decade. This notwithstanding, the share of population that considers crime to be a major problem in their neighbourhood of residence increased from $31.2 \%$ up to $38.9 \%$ between 1993 and 2015, as reported by ISTAT (2016) in his Annual Statistical Bulletin. As such, these figures suggest that people's perception of the reality of crime is increasingly distorted. The mismatch between actual crime rates and subjective feelings of unsafety did not go unnoticed among public authorities and the current Italian Minister of the Interior has even suggested in a recent interview with the The New York Times (2017) that fear rather than crime in itself would be "the crucial element of the next 10 years in democracy, in Italy and all the world".

\section{Addressing the Social Causes of Fear: The Social Insecurity Model}

Building further on recent developments in the field of fear of crime studies, a "social insecurity model" was conceptualized and tested with the specific objective of accounting for the country-specific characteristics of Italy. The novelty of this model lies in the conceptualization of social insecurity as a way to operationalize vulnerability and explore its relationship with people's subjective perceptions of insecurity. In fact, in the field of studies on victimization and the fear of crime, vulnerability is usually analysed in terms of the likelihood of individuals' involvement as the victims of a crime, while comparatively less attention has been paid to the social determinants of vulnerability.

With this in mind, the model of social insecurity graphically represented in Fig. 1 is intended to aid in the exploration of whether factors associated with social vulnerability may predict subjective feelings of unsafety. In particular, the theoretical construct labelled social vulnerability addresses two different but complementary sub-dimensions, 


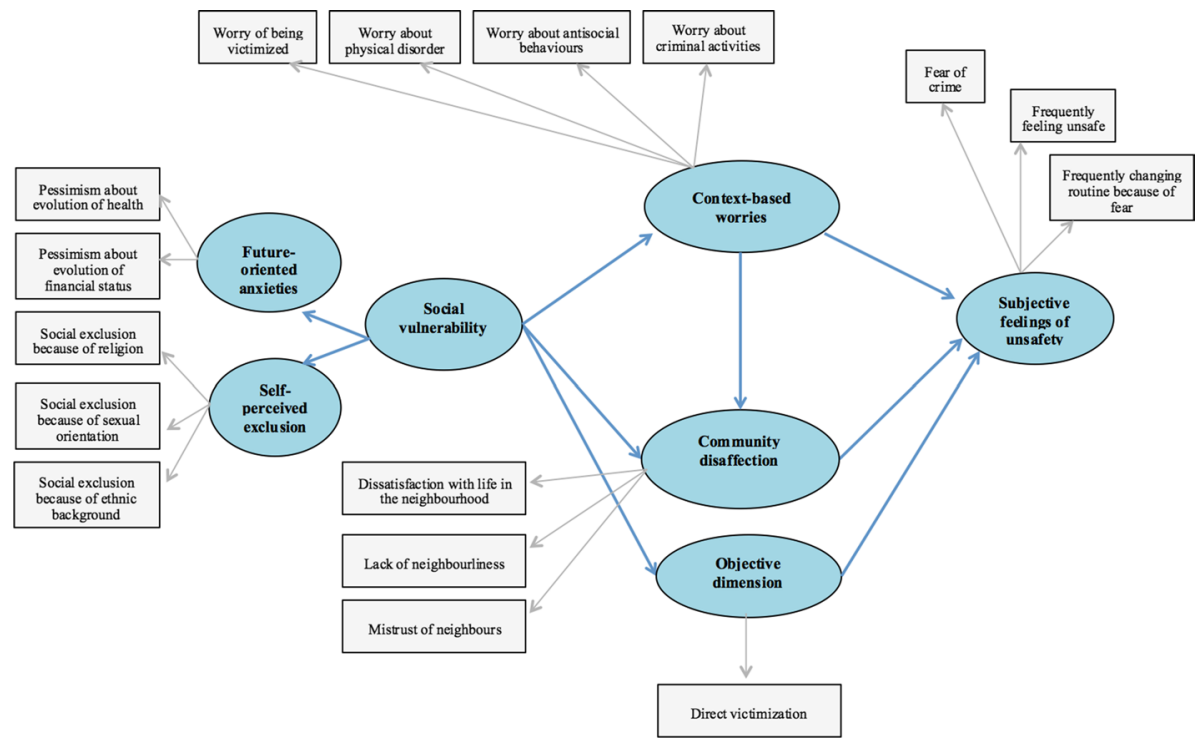

Fig. 1 Path diagram illustrating the model of social insecurity. Observed variables are shown in boxes, whereas latent factors are shown in ellipses. Directional relationships are symbolized through single-headed arrows

future-oriented anxieties and self-perceived social exclusion, where the conceptualization is based upon recent studies relating the incidence of social marginalization (Vieno et al. 2013), poor health (Jackson and Stafford 2009) and low welfare provision (Hummelsheim et al. 2011) to an explanation of subjective feelings of unsafety. Additionally, the proposed model explores whether community disaffection-in terms of dissatisfaction with life in the neighbourhood, lack of neighbourliness and mistrust of neighbours-could mediate the relationship between social vulnerability and context-based worries, on the one hand, and the subjective perception of insecurity, on the other. At the same time, the role of direct victimization within the general model is also explored.

\section{Objective}

The overarching goal of the present research is to explore the social significance of individuals' perceived insecurity by addressing their existential uncertainties within a general model of social insecurity and a comprehensive account of the results is provided in an attempt to provide an original contribution to recent debates. The results have been obtained by testing a structural equation model, labelled "social insecurity model", based on the following hypothesis: future-oriented anxieties and self-perceived social exclusion are likely to predict subjective feelings of unsafety through the moderating role of community disaffection, neighbourhood-based worries and direct experiences of victimization on this relationship. As such, the variables introduced within the model aim to provide a better definition of the notion of "vulnerability" and fill persistent gaps in the field of research of fear of crime studies. 


\section{Method}

\subsection{Data}

The analysis is drawn from a survey of 15,428 residents carried out in Italy. The sampling was stratified according to the characteristics of sex, age, nationality, educational attainment and employment. Random probability sampling of household addresses was used to implement the survey through the CATI system (Computer-Assisted Telephonic Interview). A team of survey takers was trained prior to the start of the data collection so that they were familiar with the questionnaire.

Finally, male respondents represented $46.9 \%$ of the total sample and the remaining $53.1 \%$ were female. As for the age groups, $7.9 \%$ of the respondents were aged between 18 and 25 years old, $20.5 \%$ were between 26 and 40 years old, $44.4 \%$ between 41 and 65 years old, and $27.2 \%$ were over 65 . As a result, the mean age of the sample was above the mean age of the Italian population ( 55 years old vs. 44.6) reported by the Italian National Institute of Statistics as of 1 January 2016. 92.8\% of the people surveyed were born in Italy, while foreign-born respondents accounted for $7.2 \%$ of the total sample and included 32 different nationalities. The distribution of the sample by nationality largely reflects the demographic reality of the country as measured by the Italian National Institute of Statistics, whose data indicate that as of 1 January 2016 foreign-born residents accounted for $8.3 \%$ of the total population of Italy.

$34.5 \%$ of respondents held a higher education degree, which is above the official figure on educational attainment reported by ISTAT, $41.7 \%$ had finished secondary school and $5.8 \%$ had at least a professional training course, while deficits in formal education (e.g. only primary school or dropping out before finishing primary school) were recorded in $17.9 \%$ of cases.

Looking at respondents' participation in the labour market, $30 \%$ were employed fulltime (more than $30 \mathrm{~h}$ per week) at the time of the survey, $7.3 \%$ were only employed parttime (between 8 and 29 h per week), while another $0.9 \%$ had less than $8 \mathrm{~h}$ of work per week. A total of $6.3 \%$ were classified as long-term unemployed (more than 1 year out of work), $2.8 \%$ had been unemployed for less than 1 year, $0.2 \%$ were not working due to precarious health conditions, and $0.1 \%$ were neither working nor looking for a job. As such, the unemployment rate of the respondents is close to the up-to-date figures published by ISTAT showing that, as of May 2017, the unemployment rate in Italy was $11.3 \%$. Retirees accounted for $27.9 \%$ of the total sample, the self-employed were $9.2 \%$, while people engaged in some type of domestic work represented $8.8 \%$ of the sample. Finally, $6.6 \%$ of respondents reported being full-time students or serving an internship.

\subsection{Instrument}

Desk-based reviews of five victimization surveys at the EU level were used to inform a process of participatory design for a new thematic questionnaire. The following surveys were considered: Cadre de vie et sécurité (France), Crime Survey for England and Wales (UK), Encuesta de Seguridad Pública de Cataluña (Spain), Sicurezza dei cittadini (Italy) and Victims and Opinion Research (Hungary). Based on the inputs of the desk-based review, a multidisciplinary panel of 12 independent experts were involved in a Delphi iterative design process. The Delphi method is a research technique used for converging opinions 
among experts within certain topic areas (Dalkey 1969) and, in this particular case, it was devoted to the selection of a set of items enabling a comprehensive assessment of the role played by social vulnerability in determining people's feelings of unsafety. The experts were selected to represent different fields of expertise (criminology, sociology, social psychology, and crime statistics) and their institutional affiliation varied from academia and research institutes to public institutions dealing with security issues, which ensured a multidisciplinary approach to the questionnaire's design. Details about the panel's composition and its functioning can be found in Valente et al. (2018). The items presenting higher reliability according to the experts' views were selected and included in the final version of the questionnaire, which was piloted among a pure random probability sample of households in Italy. The resulting questionnaire was consistent with previous studies although, in line with the inputs from the panel, it included a broader set of independent variables in order to focus on some aspects that had been poorly addressed up to the present, such as those involved with measuring the perception of insecurity and its correlation with social vulnerability. The full version of the questionnaire, titled the "MARGIN Questionnaire on Perception of Insecurity" (2016), is publicly available.

\subsection{Measures}

The topics of the survey analysed in the present article are: (1) social vulnerability, aimed at addressing socially constructed anxieties and self-perceived social exclusion; (2) context-based worries, referring to people's concerns regarding physical and social disorder within their place of residence; (3) community disaffection, in terms of mistrust of neighbours, lack of neighbourliness and dissatisfaction with life in the neighbourhood; (4) the objective dimension of insecurity, in terms of respondents' direct experiences with violent crime, property crime and victimization; (5) subjective feelings of unsafety, relating to fear of crime, the frequency of feeling unsafe and the frequency of changing routines because of fear.

These five theoretical constructs account for a total of 16 variables and yielded a Cronbach's $\alpha=.800$ for the global scale and the following values for each factor: $\alpha=.755$ for social vulnerability; $\alpha=.821$ for context-based worries; $\alpha=.689$ for community disaffection; $\alpha=.695$ for subjective feelings of unsafety. The measure of internal consistency for the objective dimension is not available given that this construct is composed of one single item operationalized through a filter question focusing on whether the respondent had been the victim of a crime over the 12 months preceding the survey.

The theoretical dimension labelled "social vulnerability" is made up of two different but interrelated sub-dimensions. The first sub-dimension, named "future-oriented anxieties", was intended to explore the extent to which respondents felt that their health and/ or financial situation might worsen over the 12 months after the survey. The response options ranged on a 10-point scale from "totally disagree" to "totally agree". The second sub-dimension of social insecurity, labelled "self-perceived exclusion", included questions asking respondents whether they felt looked down upon by others due to religious beliefs, ethnic/racial background, or sexual orientation, all of which were captured on a 10-point scale ranging from "totally disagree" to "totally agree".

The construct labelled "context-based worries" was measured by asking respondents how worried they were about a list of problems affecting their neighbourhood. The respondents were asked to rate on a scale from 1 (not worried at all) to 10 (very worried) the following four problems: drug trafficking and other illegal behaviour in 
public spaces; the perceived likelihood of becoming the victim of a crime in the neighbourhood in which they reside; anti-social behaviours (people hanging around making noise, being drunk, littering public spaces); and poor condition of urban furniture (poor lighting, vandalized property, deteriorated houses, abandoned cars).

The dimension labelled "community disaffection" was measured by asking respondents to rate on a scale from 1 (totally agree) to 10 (totally disagree) three statements referring to their satisfaction with life in the neighbourhood, the level of trust among neighbours (i.e., whether they could get help from neighbours in case of need) and the perceived degree of neighbourliness.

As previously mentioned, the question addressing past victimization experiences identifies what we have labelled the "objective dimension" of insecurity in contrast with subjective feelings that could engender fear even in the absence of any personal experiences with crime. Respondents were asked if they had been the victims of a crime over the 12 months prior to the survey. Two typologies of crime were addressed: crimes against property (i.e. burglary of dwelling, theft of personal objects and vehicle-related thefts), and violent/contact crimes (i.e. robbery, threats, assaults and sexual assault).

Lastly, the construct labelled "subjective feelings of unsafety" included three items designed to provide a comprehensive account of the psychological dimension of insecurity. The items respectively asked: (a) how frequently respondents feel unsafe in their neighbourhood, (b) how frequently they change their plans and/or routine to avoid situations that make them feel unsafe and (c) how unsafe they feel when walking alone in the neighbourhood after dark. A 10-point Likert scale was used for all three items: in the first two cases the scale ranged from "never" to "very often", while the latter item was measured on a scale ranging from "very safe" to "very unsafe". As a result, by including a focus on the frequency of feelings of unsafety and the potential consequences on people's daily routines, it would be possible to test a conceptual model that could overcome the reductionist approach to insecurity as a mere consequence of crime-related issues.

Table 1 provides the data description referring to the different items informing the conceptualization of the theoretical constructs addressed by this paper.

\subsection{Analytical Approach}

Relations between latent factors were explored by approximating the assumptions of the Structural Equation Model (SEM). Structural Equation Modeling allows for an evaluation of the adjustment of the theoretical model and for an exploration of whether it is consistent with underlying patterns in the data. Since the distribution of many variables is skewed, Weighted Least Squares Estimation (WLS) was preferred to standard maximum likelihood (MLE) as the estimation of the model's adjustment to the data. WLS was the preferred choice also considering that it is recommended for fit of models with categorical observed variables (Muthén 1984). A resampling procedure based on the bootstrap method was used to construct confidence intervals and to estimate the parameters. Bootstrapped standard errors were computed using 1000 draws. Missing values were not replaced or imputed but dealt with by using full information maximum likelihood. Mplus software, version 5.1, was used for that process. Details on the strength of consistency of the model of social insecurity are provided below. 
Table 1 Data description

\begin{tabular}{lllll}
\hline Constructs & Items & N & Mean & SD \\
\hline Social vulnerability & Pessimism towards evolution of health & 14,460 & 3.86 & 2.704 \\
& Pessimism towards evolution of financial condi- & 14,867 & 4.46 & 2.844 \\
& tion & & & \\
& Feeling excluded because of religious beliefs & 15,089 & 2.06 & 2.161 \\
& Feeling excluded because of ethnic background & 15,130 & 1.89 & 2.045 \\
& Feeling excluded because of sexual orientation & 11,963 & 1.81 & 1.962 \\
& Worry about criminality & 14,814 & 5.16 & 3.018 \\
Context-based worries & Worry about anti-social behaviours & 15,320 & 5.07 & 2.997 \\
& Worry about risk of victimization & 15,079 & 5.15 & 2.953 \\
& Worry about poor condition of urban furniture & 15,302 & 5.12 & 2.935 \\
& Mistrust of neighbours & 15,227 & 5.07 & 2.620 \\
Community disaffection & Lack of neighbourliness & 15,327 & 5.56 & 2.586 \\
& Dissatisfaction with life in the neighbourhood & 15,404 & 3.30 & 2.299 \\
& Direct victimization & 15,363 & 0.09 & 0.284 \\
Objective dimension & Frequency of the feeling of unsafety & 15,307 & 4.36 & 2.639 \\
Subjective feelings of unsafety & Frequency of changing routines because of fear & 15,282 & 3.30 & 2.659 \\
& Fear of crime & 14,963 & 5.08 & 2.737 \\
\hline & & &
\end{tabular}

\section{Results}

As a result of the operationalization of the theoretical constructs discussed above, a social insecurity model including 16 variables was designed and tested. The model was integrated by four first-order factors respectively identifying the constructs labelled context-based worries, community disaffection, objective dimension and subjective feelings of unsafety, plus a second-order factor addressing the two sub-dimensions of social vulnerability. A representation of the model can be appreciated below in Fig. 2 summarizing the standardized estimates of each parameter in the measurement model.

Fit indices are all satisfactory except for the Chi Square $\left(x^{2}=4599 ; \mathrm{df}=95 ; p<.001\right)$ statistic of fit. However, as argued by Schermelleh-Engel et al. (2003), the $x^{2}$ statistic is highly sensitive to sample size and it is no longer relied upon as a sole measure for acceptance or rejection. The Comparative Fit Index and the Tucker Lewis Index showed values above the threshold $.90(\mathrm{CFI}=.959$; TLI $=.948)$, the Root Mean Square Error of Approximation (RMSEA) is .055 and the examination of the results of the standardized model indicates that all paths are statistically significant $(p<.001)$. Looking at the results of the Sobel's test (Sobel 1982) summarized in the Table 2 underneath, the standard errors for the indirect effects within our model range between 0.002 and 0.022 , thus indicating statistical significance $(p<.001)$ for all of them.

In addition, according to the bias-corrected bootstrap confidence interval, the indirect effects between social vulnerability and the subjective feelings of unsafety are significant at the $1 \%$ level considering that neither the $95 \%$ confidence interval nor the $99 \%$ confidence interval around the indirect effect includes the values of zero (see Table 3).

The unmeasured latent method construct (Podsakoff et al. 2012) was conducted to test for the existence of common method bias by comparing two measurement models, one with common method factor where all the path coefficients were assumed to be equal and 


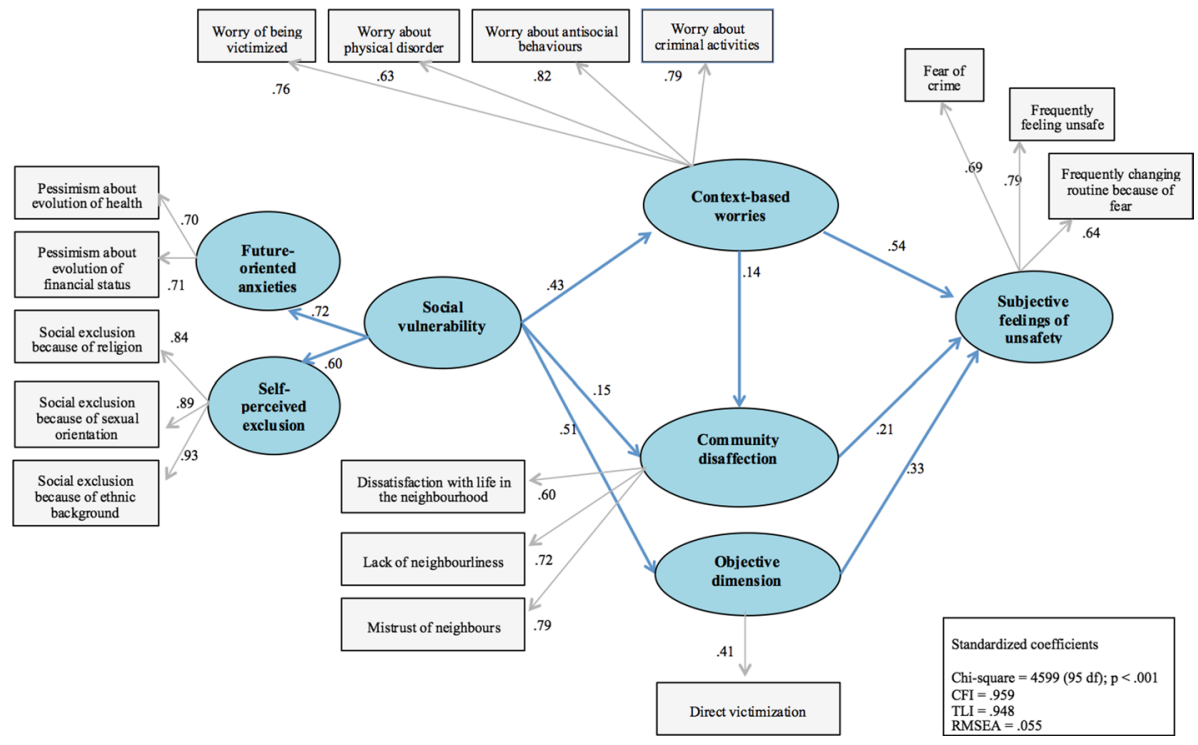

Fig. 2 Structural equation model exploring the predictive effect of social vulnerability on subjective feelings of unsafety within a general model of social insecurity

Table 2 Standardized specific indirect effects

\begin{tabular}{|c|c|c|c|c|}
\hline Specific indirect effects & Estimate & SE & $\mathrm{t}$ & $p$ value \\
\hline $\begin{array}{l}\text { Social vulnerability } \rightarrow \text { subjective feelings of unsafety } \\
\text { VIA context-based worries }\end{array}$ & 0.233 & 0.011 & 20.482 & 0.000 \\
\hline $\begin{array}{l}\text { Social vulnerability } \rightarrow \text { subjective feelings of unsafety } \\
\text { VIA community disaffection }\end{array}$ & 0.032 & 0.006 & 5.159 & 0.000 \\
\hline $\begin{array}{l}\text { Social vulnerability } \rightarrow \text { subjective feelings of unsafety } \\
\text { VIA objective dimension }\end{array}$ & 0.167 & 0.022 & 7.498 & 0.000 \\
\hline $\begin{array}{l}\text { Social vulnerability } \rightarrow \text { subjective feelings of unsafety } \\
\text { VIA context-based worries and Community disaffection }\end{array}$ & 0.013 & 0.002 & 6.793 & 0.000 \\
\hline
\end{tabular}

constrained to a common factor, and the other without common method factor. The difference in standardized estimates of the two measurement models is below the cut-off value of 0.25 , thus suggesting the absence of common method bias in the current study.

Composite reliability (CR) and average variance extracted (AVE) were computed to confirm the model structure, as presented in Table 4. Composite reliability was used to measure the factors' internal consistency, where values above the threshold .60 indicated good reliability (Bagozzi and Yi 1988). For convergent validity, the values of the average variance extracted approximating the threshold .50 are considered acceptable according to Netemeyer et al. (2003).

The interpretation of the model corroborates the hypothesis that social vulnerability is likely to predict subjective feelings of unsafety by considering the moderating role played by objective insecurity (i.e., direct victimization), socio-geographic insecurity (i.e., context-based worries) and community disaffection. At the same time, the results 


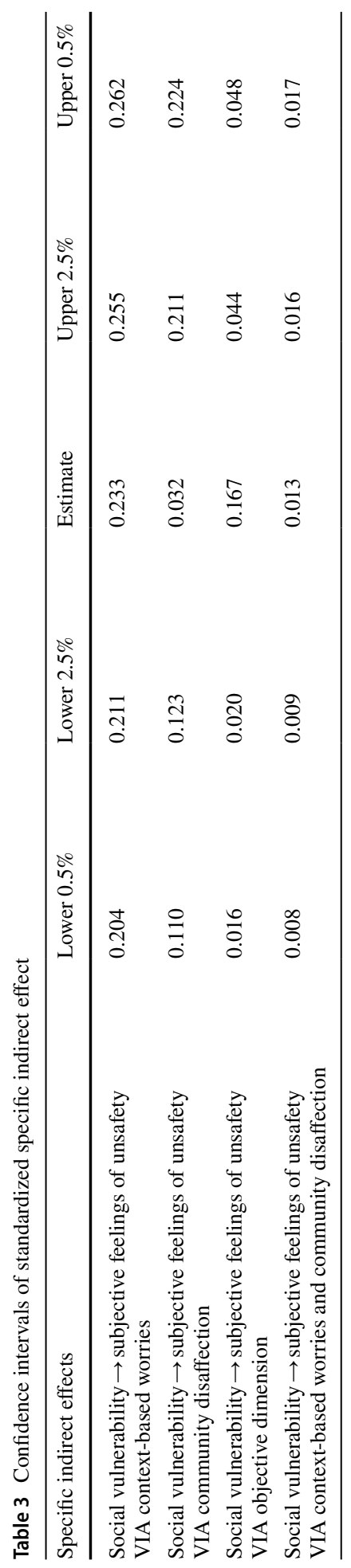


Table 4 Table showing the standardised factor loadings $(\lambda)$, the composite reliability (CR) and the average variance extracted (AVE)

\begin{tabular}{lllll}
\hline Constructs & Items & $\lambda$ & CR & AVE \\
\hline Social vulnerability & Pessimism towards evolution of health & .70 & .91 & .67 \\
& Pessimism towards evolution of financial condition & .71 & & \\
& Feeling excluded because of religious beliefs & .84 & & \\
& Feeling excluded because of ethnic background & .93 & & \\
& Feeling excluded because of sexual orientation & .89 & & \\
Context-based worries & Worry about criminality & .79 & .84 & .57 \\
& Worry about anti-social behaviours & .82 & & \\
& Worry about risk of victimization & .76 & & \\
& Worry about poor condition of urban furniture & .63 & & \\
Community disaffection & Mistrust of neighbours & .70 & .75 & .50 \\
& Lack of neighbourliness & .72 & & \\
& Dissatisfaction with life in the neighbourhood & .60 & & \\
Objective dimension & Direct victimization & .41 & N/A & N/A \\
Subjective feelings of unsafety & Frequency of the feeling of unsafety & .72 & .75 & .50 \\
& Frequency of changing routines because of fear & .79 & & \\
& Fear of crime & .69 & & \\
\hline
\end{tabular}

suggest that the contribution of the factor labelled community disaffection to the general model is relatively modest, which seems to be consistent with the conclusions of Kanan and Pruitt (2002), who found in their analysis of the survey implemented in Nashville (Tennessee) that neighbourhood integration variables appeared to be relatively unimportant in determining fear of crime.

A further test was carried out by implementing a partial mediation model where the latent factor labelled social vulnerability has both direct and indirect effects on the latent factor named subjective feelings of unsafety. In other words, the newly designed model encompasses an additional path compared to an otherwise identical model: the direct link between socially constructed fears, on one hand, and the subjective dimension, on the other. All fit indices remained unchanged and the estimation of the main effects outlined in this second model indicates that the contribution of social vulnerability is statistically significant $(\beta=.093 ; z=4.02 ; p<.001)$, although the strength of its effect on the latent construct subjective feeling of unsafety is rather restricted. Concretely, the parameter estimate $(\beta)$ of the direct effect between these two latent factors is close to zero in the completely standardized solution. Yet, consistent with the outputs of the complete mediation model, the exogenous latent variable significantly affects the subjective dimension of unsafety via the moderating factors related to people worries about the social and physical deterioration of the neighbourhood, the dissatisfaction with life at the community level, and previous experiences with direct victimization. As a result, the differences between the partial mediation model and the complete mediation model are subtle. In an attempt to establish an objective criterion for a decision between these two competing models, a $x^{2}$ difference test was computed. The test revealed a non-significant $x^{2}$ difference value, which leads to the conclusion that both models fit equally well statistically, yet with slightly different theoretical implications. In fact, the partial 
mediation model suggests that, under certain circumstances, future-oriented anxieties and self-perceived stigmatization could directly fuel crime-related fears.

\section{Discussion and Conclusions}

The analysis presented above introduces an alternative approach to address the social determinants of people's fears and explore the impact of socially constructed insecurities on the perception of insecurity. The interpretation of the results showed general support for the underlying hypothesis of the research by providing evidence for the predictive role of social vulnerability on neighbourhood-based worries, victimization patterns and community cohesion. In turn, the combination of social vulnerability and the three moderating factors may predict people's subjective feelings of unsafety. Moreover, as shown in the partial mediation model, social vulnerability may also exert direct influence on the subjective feelings of unsafety, although to a lesser extent.

Ecological analyses have already stressed the importance of neighbourhood characteristics (i.e., where crime-related concerns take place) when it comes to explaining variations in terms of perceived insecurity. In the case of our analysis, neighbourhood-based concerns expressed as residents' worries about physical and social disorder, as well as the perceived risk of being involved in a crime within the neighbourhood, were shown to have a significant effect on subjective feelings of unsafety. This finding endorses the conclusions of previous studies in the field of research on neighbourhood effects and reinforces the assumption that "place matters" (Weisburd et al. 2016) when trying to understand the determinants of public and personal insecurity.

On the other hand, the results provide less support than expected a priori for the idea that people's feeling of integration within a neighbourhood influences their perception of insecurity. As mentioned previously, this supposition could be interpreted along the same lines as Kanan and Pruitt (2002) who have shown that neighbourhood integration is not significant in determining fear of crime. Although some authors have provided evidence on the inverse relationship between social integration and fear of crime (Hale 1996), other scholars have found more controversial results (Hartnagel 1979; Kennedy and Silverman 1985; Yuan and McNeeley 2015). As such, the conclusions of previous research would suggest that caution is warranted when trying to draw conclusions on the effect of social integration on fear of crime. Perceived lack of neighbourhood cohesion could be the consequence of broader changes such as the arrival of newcomers within the neighbourhood that alter the status quo of the community, the occupation of public spaces by groups perceived as threatening, changes in the urban layout, etcetera. In these cases, the increase in the perception of insecurity would be closely associated with social disorder and a potential threat rather than to the lack of community cohesion in itself.

Regarding the impact of victimization, previous research has demonstrated that direct experiences with crime may produce negative and long-lasting physical and/or psychological effects. At the same time, following the conclusions of Tseloni and Zarafonitou (2008), victimization is just one element of the broader problem of security, given that people may feel unsafe even without having previously been the victim of a crime. In our case, although direct victimization did prove to have a significant effect on the subjective elements of insecurity, it had comparatively less influence than perceived disorder.

Finally, the outputs of the structural model analysed point to the influence of social vulnerability on the subjective feelings of unsafety. Future-oriented and anxiety-provoking 
situations both play a prominent role in people's understanding of security issues, which recalls the idea of Robert Castel, who interpreted social insecurity as a combination of social, economic and power inequalities or, borrowing his own words, "an event that confines an individual's ability to care for his or her own social independence" (Castel 2004: 35). What is more, the feeling of being isolated, left out, or looked down upon by others due to religious beliefs, ethnic background or sexual orientation seem to exert a prominent influence on people's subjective feelings of unsafety, which represents a totally original conclusion compared with previous studies. Building further on the conclusions of past research which already indicated that "it is not always crime which is meant when crime is spoken about" (Hirtenlehner 2008: 134) and fear of crime might be confused with different types of risks, the present study goes beyond and highlights that people's feelings of unsafety could be based on social grounds.

Social vulnerability and stigmatization appear then as strongly interlinked processes. As noted by Di Masso et al. (2014), the perception of being excluded could lead to self- and/or hetero-attributions related to security threats that, in turn, originate episodes of discrimination, social rejection and social sorting. These processes have been proven to have consequences over the basis of civil coexistence in contemporary cities (Di Masso 2015). Other consequences can be directly derived from results obtained in the present research: because of increasing subjective feelings of unsafety, individuals and/or social groups might be either pushed to withdrawal from public places perceived as threatening or to confine their daily activities to selected places conceived as a sort of shelter within the social space. Both dynamics lead to spatial stigmatization, social segmentation of urban spaces and, in the end, to the loss of the democratic nature of coexistence (Thwaites et al. 2013).

The conclusions arising from our analysis are thus supposed to have implications both within and beyond the academic community. First of all, having established that individuals are experiencing an increasing misperception between concrete experiences with crime and socially constructed anxieties, public authorities and civil society are invited to look closer at the fear of crime and tackle structural causes of contemporary uncertainty. Moreover, our results endorse a knowledge-based approach oriented towards the analysis of people's insecurities at the finest possible geographic level (e.g. neighbourhood or street blocks) and a focus on the determinants of insecurity among specific social groups (e.g. minorities, vulnerable groups, etc.) as a means of designing ad hoc policies that foster neighbourliness and urban coexistence.

It should nevertheless be stressed that the following issues limited the scope of the current research. First, the analysis is based on a cross-sectional study and future work is needed to evaluate the potential influence that could be played by demographic and socioeconomic predictors within the social insecurity model. Second, as with any survey, the number of questions that respondents can be asked is limited. Accordingly, other types of self-perceived exclusions, such as those related to class position could have been considered but they did not reach the required threshold during the questionnaire design process. At the same time, the lack of questions related to the topic of cyber-victimization, at a time when cybercrime is increasing (European Commission, 2012), is also an issue although this topic was beyond the scope of the current research. Third, this study also shares some limitations traditionally affecting victimization surveys, such as the fact that respondents are asked to remember crime experiences retrospectively or focus on static feelings of unsafety preventing an analysis of their evolution over time. Finally, the relationship between community (dis)affection and people's perceived (in)security should be put into context, bearing in mind that the very idea of "community" could be problematic especially in the framework of a survey that has been carried out on a national scale. More 
broadly, bearing in mind the potential cultural differences between countries in terms of what is and isn't a threat for personal and public security, our results should be interpreted in close relation with the specific context in which the survey took place.

These limitations may, however, open new avenues of future research focusing on crossnational cultural differences, the effects of cybercrime on perceived insecurity, as well as the relationship between the times and places where victimization and feelings of insecurity are more likely to occur. Alternative models to study the moderating role of a number of alternative factors should also be tested in the future. Finally, building further on current developments that have gathered solid evidence on the causes of people's fears, future research could be carried out to broaden our understanding of the consequences of these fears on people's attitudes, judgments and decisions.

In summary, the present research serves as a first attempt to operationalize new concepts leading to a redesign of some parts of victimisation surveys commonly used to measure and account for fear of crime, in particular by broadening the definition of vulnerability beyond the mere consideration of the likelihood of individuals' involvement as the victims of a crime. This type of approach is consistent with the reality in Italy where, on the one hand, official data point to falling crime rates but concurrent increases in the perception of insecurity while, on the other, our survey shows that respondents are affected by socially constructed fears rather than simply those related to crime. In the end, these outcomes may offer an explanation for the mismatch between actual crime and subjective insecurity and, more broadly, foster a new branch of the literature focused on the social determinants of fear.

Acknowledgements The content of the proposed manuscript is based on the work carried out in the framework of the Project "MARGIN-Tackle Insecurity in Marginalized Areas" (2015-2017), funded by the European Union under the Horizon 2020 programme (Grant Agreement No. 653004).

\section{References}

Bagozzi, R. P., \& Yi, Y. (1988). On the evaluation of structural equation models. Journal of the Academy of Marketing Science, 16(1), 74-94.

Bannister, J., Fyfe, N., \& Kearns, A. (2006). Respectable or respectful? (In)civility and the city. Urban Studies, 43(5-6), 919-937.

Castel, R. (2004). La inseguridad social. ¿Qué es estar protegido?. Buenos Aires: Manantial.

Cossman, J. S., \& Rader, N. E. (2011). Fear of crime and personal vulnerability: Examining self-reported health. Sociological Spectrum, 31(2), 141-162.

Dalkey, N. C. (1969). An experimental study of group opinion. Futures, 1(5), 408-426.

Di Masso, A. (2015). Micropolitics of public space: On the contested limits of citizenship as a locational practice. Journal of Social and Political Psychology, 3(2), 63-83.

Di Masso, A., Castrechini, A., \& Valera, S. (2014). Displacing xeno-racism: The discursive legitimation of native supremacy through everyday accounts of 'urban insecurity'. Discourse \& Society, 25, 341-361.

European Commission. (2012). Special Eurobarometer 390: Cyber security. http://ec.europa.eu/public_ opinion/archives/ebs/ebs_390_en.pdf. Accessed January 20, 2017.

Eurostat. (2013). Statistics in focus 4/2013. http://ec.europa.eu/eurostat/documents/3433488/5585688/KSSF-13-004-EN.PDF/dffc573c-e96c-45b7-a826-e110023d00c0. Accessed March 21, 2018.

Ferraro, K. F. (1995). Fear of crime: Interpreting victimization risk. Albany: State University of New York Press.

Franklin, T. W., Franklin, C. A., \& Fearn, N. E. (2008). A multilevel analysis of the vulnerability, disorder, and social integration models of fear of crime. Social Justice Research, 21(2), 204-227.

Hale, C. (1996). Fear of crime: A review of the literature. International Review of Victimology, 4, 79-150.

Hanslmaier, M. (2013). Crime, fear and subjective well-being: How victimization and street crime affect fear and life satisfaction. European Journal of Criminology, 10(5), 515-533. 
Hartnagel, T. (1979). The perception and fear of crime: Implications for neighbourhood cohesion, social activity, and community affect. Social Forces, 58(1), 176-193.

Hinkle, J. (2015). Emotional fear of crime vs. perceived safety and risk: Implications for measuring "fear" and testing the broken windows thesis. American Journal of Criminal Justice, 40, 147-168.

Hirtenlehner, H. (2008). Disorder, social anxieties and fear of crime: Exploring the relationship between incivilities and fear of crime with a special focus on generalized insecurities. In H. Kury (Ed.), Fear of crime-Punitivity. New developments in theory and research (pp. 127-158). Bochum: Universitätsverlag Brockmeyer.

Hummelsheim, D., Hirtenlehner, H., Jackson, J., \& Oberwittler, D. (2011). Social insecurities and fear of crime: A cross-national study on the impact of welfare state policies on crime-related anxieties. European Sociological Review, 27(3), 327-345.

Hunter, A. (1978). Symbols of incivility: Social disorder and fear of crime in urban neighbourhoods. Paper presented at the annual meeting of the American Society of Criminology. Dallas, TX.

ISTAT - Istituto Nazionale di Statistica (2016). Annuario statistico Italiano. Capito 6-Giustizia, criminalità e sicurezza. https://www.istat.it/it/files/2016/12/C06.pdf. Accessed December 8, 2017.

ISTAT - Istituto Nazionale di Statistica. (2017). Rapporto annuale 2017. La situazione del Paese. https ://www.istat.it/it/files/2017/05/RapportoAnnuale2017.pdf. Accessed December 8, 2017.

Jackson, J. (2009). A psychological perspective on vulnerability in the fear of crime. Psychology, Crime and Law, 15(4), 365-390.

Jackson, J. (2011). Revisiting risk sensitivity in the fear of crime. Journal of Research in Crime and Delinquency, 48(4), 513-537.

Jackson, J., \& Stafford, M. (2009). Public health and fear of crime: A prospective cohort study. British Journal of Criminology, 49(6), 832-847.

Kanan, J., \& Pruitt, M. V. (2002). Modeling fear of crime and perceived victimization risk: The (in)significance of neighborhood integration. Sociological Inquiry, 72(4), 527-548.

Kennedy, L. W., \& Silverman, R. A. (1985). Perception of social diversity and fear of crime. Environment and Behavior, 17(3), 275-295.

Killias, M. (1990). Vulnerability: Towards a better understanding of a key variable in the genesis of fear of crime. Violence and Victims, 5(2), 97-108.

Kohm, S. A. (2009). Spatial dimensions of fear of crime in a high-crime community: Fear of crime or fear of disorder? Canadian Journal of Criminology and Criminal Justice, 51(1), 1-30.

MARGIN Questionnaire on Perception of Insecurity. (2016). http://marginproject.eu/wp-content/uploa ds/2016/10/MARGIN-questionnaire-on-perception-of-insecurity.pdf. Accessed December 8, 2017.

McNamara, N., Stevenson, C., \& Muldoon, O. T. (2013). Community identity as resource and context: A mixed method investigation of coping and collective action in a disadvantaged community. European Journal of Social Psychology, 43(4), 393-403.

Ministero dell'Interno. (2017). Dossier Viminale. Ferragosto 2017. http://www.interno.gov.it/sites/defau 1t/files/modulistica/dossier_15_agosto.pdf. Accessed December 8, 2017.

Muthén, B. (1984). A general structural equation model with dichotomous, ordered categorical, and continuous latent variable indicators. Psychometrika, 49, 115-132.

Netemeyer, R. G., Bearden, W. O., \& Sharma, S. (2003). Scaling procedures. Issues and applications. Thousand Oaks: Sage Publications.

Panzanis, C. (2000). 'Fear of crime', vulnerability and poverty. British Journal of Criminology, 40, 414-436.

Perloff, L. S. (1983). Perceptions of vulnerability to victimization. Journal of Social Issues, 39, 41-61.

Phillips, T., \& Smith, P. (2006). Rethinking urban incivility research: Strangers, bodies and circulations. Urban Studies, 43(5), 879-901.

Pitner, R. O., Yu, M. S., \& Brown, E. (2012). Making neighbourhoods safer: Examining predictors of residents' concerns about neighbourhood safety. Journal of Environmental Psychology, 32, 43-49.

Podsakoff, P. M., MacKenzie, S. B., \& Podsakoff, N. P. (2012). Sources of method bias in social science research and recommendations on how to control it. Annual Review of Psychology, 63, 539-569.

Pratt, T. C., \& Turanovic, J. J. (2015). Lifestyle and routine activity theories revisited: The importance of "risk" to the study of victimization. Victims \& Offenders, 00, 1-20.

Rader, N. E. (2004). The threat of victimization: A theoretical reconceptualization of fear of crime. Sociological Spectrum, 24(6), 399-425.

Rader, N. E., Cossman, J. S., \& Porter, J. R. (2012). Fear of crime and vulnerability: Using a national sample of Americans to examine two competing paradigms. Journal of Criminal Justice, 40, 134-141.

Reid, L. W., \& Konrad, M. (2004). The gender gap in fear: Assessing the interactive effects of gender and perceived risk on fear of crime. Sociological Spectrum, 24(4), 399-425. 
Rizzo, G. (2017). Un paese in galera. Internazionale. https://www.internazionale.it/reportage/giuseppe-rizzo /2017/09/18/carcere-italia. Accessed December 8, 2017.

Sacco, V. F., \& Glackman, W. (1987). Vulnerability, locus of control and worry about crime. Canadian Journal of Community Mental Health, 6, 99-111.

Sampson, R. J. (2012). Great American city: Chicago and the enduring neighborhood effect. Chicago: Chicago University Press.

San Juan, C., Vozmediano, L., \& Vergara, A. (2012). Self-protective behaviours against crime in urban settings: An empirical approach to vulnerability and victimization models. European Journal of Criminology, 9(6), 652-667.

Scannell, L., \& Gifford, R. (2010). Defining place attachment: A tripartite organizing framework. Journal of Environmental Psychology, 30(1), 1-10.

Schermelleh-Engel, K., Moosbrugger, H., \& Müller, H. (2003). Evaluating the fit of structural equation models: Tests of significance and descriptive goodnessof-fit measures. Methods of Psychological Research Online, 8(2), 23-74.

Sobel, M. E. (1982). Asymptotic confidence intervals for indirect effects in structural equation models. In S. Leinhardt (Ed.), Sociological methodology (pp. 290-312). Washington, DC: American Sociological Association.

Swatt, M. L., Varano, S. P., Uchida, C. D., \& Solomon, S. E. (2013). Fear of crime, incivilities, and collective efficacy in four Miami neighborhoods. Journal of Criminal Justice, 41, 1-11.

The New York Times. (2017). Italy's 'lord of the spies' takes on a migration crisis. https://www.nytim es.com/2017/08/04/world/europe/italy-marco-minniti-migration.html?mcubz=0. Accessed December 8, 2017.

Thwaites, K., Mathers, A., \& Simkins, I. (2013). Socially restorative urbanism. London: Routledge.

Tseloni, A., \& Zarafonitou, C. (2008). Fear of crime and victimization. A multivariate multilevel analysis of competing measurements. European Journal of Criminology, 5(4), 387-409.

Valente, R., Crescenzi, L., \& Chainey, S. (2018). Participatory design of a thematic questionnaire in the field of victimization studies. European Journal of Criminology. https://doi.org/10.1177/1477370818 769597 (article first published online: 25 April 2018).

Valera, S., \& Guàrdia, J. (2014). Perceived insecurity and fear of crime in a city with low-crime rates. Journal of Environmental Psychology, 38, 195-205.

Van Ham, M., Manley, D., Bailey, N., Simpson, L., \& Maclennan, D. (Eds.). (2012). Neighbourhood effects research: New perspectives. Dordrecht: Springer.

Vieno, A., Roccato, M., \& Russo, S. (2013). Is fear of crime mainly social and economic insecurity in disguise? A multilevel multinational analysis. Journal of Community \& Applied Social Psychology, 23, 519-535.

Weisburd, D., Eck, J. E., Braga, A. A., Telep, C. W., Cave, B., Bowers, K., et al. (2016). Place matters: Criminology for the twenty-first century. Cambridge: Cambridge University Press.

Wilson, J. Q., \& Kelling, G. L. (1982). Broken Windows. Atlantic Monthly, 211, 29-38.

Wyant, B. R. (2008). Multilevel impacts of perceived incivilities and perceptions of crime risk on fear of crime. Journal of Research in Crime and Delinquency, 45, 39-64.

Yuan, Y., \& McNeeley, S. (2015). Social ties, collective efficacy, and crime-specific fear in seattle neighborhoods. Victims \& Offenders, 00, 1-23. 